\title{
BMJ Open Comparison of three video laryngoscopes and direct laryngoscopy for emergency endotracheal intubation: a retrospective cohort study
}

Kei Suzuki, ${ }^{1}$ Shinji Kusunoki, ${ }^{2}$ Koichi Tanigawa, ${ }^{3}$ Nobuaki Shime ${ }^{1}$

To cite: Suzuki K, Kusunoki S, Tanigawa K, et al. Comparison of three video laryngoscopes and direct laryngoscopy for emergency endotracheal intubation: a retrospective cohort study. BMJ Open 2019;9:e024927. doi:10.1136/ bmjopen-2018-024927

- Prepublication history for this paper is available online. To view these files, please visit the journal online (http://dx.doi. org/10.1136/bmjopen-2018024927).

Received 1 July 2018

Revised 17 January 2019

Accepted 26 February 2019

Check for updates

(C) Author(s) (or their employer(s)) 2019. Re-use permitted under CC BY-NC. No commercial re-use. See rights and permissions. Published by BMJ.

${ }^{1}$ Department of Emergency and Critical Care Medicine, Graduate School of Biomedical and Health Sciences, Hiroshima University, Hiroshima, Japan

${ }^{2}$ Critical Care Medical Center, Hiroshima Prefectural Hospital, Hiroshima, Japan

${ }^{3}$ Fukushima Global Medical Science Center, Fukushima Medical University, Fukushima, Japan

Correspondence to

Dr Nobuaki Shime;

nshime@hiroshima-u.ac.jp

\section{ABSTRACT}

Objective Video laryngoscopes are used for managing difficult airways. This study compared three video laryngoscopes' (Pentax-Airway Scope [Pentax], King Vision[King] and McGrath MAC [McGrath]) performances with the Macintosh direct laryngoscope (Macintosh) as emergency tracheal intubations (TIs) reference.

Design Retrospective cohort study.

Setting The emergency department (ED) and the intensive care unit (ICU) of two Japanese tertiary-level hospitals.

Participants All consecutive video-recorded emergency TI cases in EDs and ICUs between December 2013 and June 2015.

Primary outcome measures The primary study endpoint was first-pass intubation success. A subgroup analysis examined the first-pass intubation success of expert versus non-expert operators. A logistic regression analysis was performed to identify the predictors of first-pass intubation success.

Results A total of 287 emergency Tls were included. The first-pass intubation success rates were $78 \%$, $58 \%, 78 \%$ and $58 \%$ for the Pentax, King, McGrath and Macintosh instruments, respectively ( $\mathrm{p}=0.004$, Fisher's exact test). The non-expert operators' success rates were significantly higher ( $\mathrm{p}=0.00004$, Fisher's exact test) for the Pentax (87\%) and McGrath (78\%) instruments than that for the King (50\%) and Macintosh (46\%) instruments, unlike that of the experts $(67 \%, 67 \%, 78 \%$ and $78 \%$ for Pentax, McGrath, King and Macintosh, respectively; $\mathrm{p}=0.556$, Fisher's exact test). After TI indication, difficult airway characteristics, and expert versus non-expert operator parameters adjustments, the Pentax $(\mathrm{OR}=3.422$, $95 \% \mathrm{Cl} 1.551$ to $7.550 ; \mathrm{p}=0.002)$ and McGrath $(\mathrm{OR}=$ 3.758 , Cl 1.640 to $8.612 ; p=0.002$ ) instruments showed significantly higher first-pass intubation success odds when compared with the Macintosh laryngoscope (reference, $0 \mathrm{R}=1$ ). The King instrument, however, ( $\mathrm{OR}=1.056 ; 95 \% \mathrm{Cl} 0.487$ to $2.289, \mathrm{p}=0.889$ ) failed to show any significant superiority.

Conclusion The Pentax and McGrath laryngoscopes showed significantly higher emergency TI first-pass intubation success rates than the King laryngoscope when compared with the Macintosh laryngoscope, especially for non-expert operators.

Trial registration number UMIN000027925; Results.
Strengths and limitations of this study

To our knowledge, this study is the first to directly compare three different video laryngoscopes (Pentax-Airway Scope, King Vision, McGrath MAC) and the Macintosh laryngoscope for emergency tracheal intubation (TI).

- The strength of this study is that we precisely evaluated the intubation process among four laryngoscopes using real-world video records of TI.

- The major limitation of this study is its observational design. Although we tried to adjust for almost all possible confounding factors based on previous studies, we could not completely exclude the influence of other confounding factors on the results.

\section{BACKGROUND}

Tracheal intubation (TI) performed in the emergency setting is more challenging than when attempted in an operating room due to patient, operator and environment-associated factors. ${ }^{1-3}$ Consequently, the success rate is lower, the time needed to undertake the TI is longer, and the complication rate is higher. $^{1245}$

Video laryngoscopes (VLs) are increasingly used to increase the safety and success rates of emergency TIs. Among others, the VLs used in clinical practice include the PentaxAirway Scope (Pentax), the King Vision (King) and the McGrath MAC (McGrath). VLs are classified according to the guidance method of the tracheal tube. The Pentax and King VLs are L-shaped, with an attachment of the tracheal tube to the blade, while McGrath has no attachment, which facilitates the flexible orientation of the tube. Compared with the Macintosh laryngoscope (Macintosh), the superiority of VLs in viewing the glottis and in successfully completing TIs has been confirmed in a manikin model ${ }^{6}$ and in patients undergoing elective surgery. ${ }^{7-10}$ However, a randomised trial in intensive care 
units (ICUs) showed no difference in first-pass intubation success rates between VLs and the Macintosh system. ${ }^{11} \mathrm{~A}$ systematic review of emergency TIs in emergency departments (EDs) and ICUs showed that the use of VLs had no significant advantage with regard to first-attempt success rates, although their use was significantly associated with a lower number of intubation attempts. ${ }^{12}$ However, these studies included various types of VL in a single group and did not consider the characteristics of each VL. To our knowledge, no study has examined the relative performance of VLs, especially in emergency TIs.

The identification of the optimal VL is important, in view of (a) the high rate of difficult emergency TIs (10\% in the non-operative area including the ED and the ICU) and multiple intubation attempts $(11 \% \text { in the ED })^{113}$ and (b) the increased incidence of adverse events associated with unsuccessful attempts, in which more than one attempt at TI was a significant predictor of one or more adverse events (adjusted OR=7.5, 95\% CI 5.9 to 9.6). ${ }^{14}$

The aim of this study was to compare the emergency TI performances of the Pentax, King and McGrath systems with that of the Macintosh in the ED or ICU.

\section{METHODS}

\section{Study design and setting}

This retrospective, observational study was conducted at a university hospital and at a general, public hospital. Both boards waived the need to obtain patient informed consent before collecting the data. We disclosed information regarding this study on a webpage and offered an opportunity to opt out.

The ICUs of both institutions treat ambulatory and postoperative, medical and surgical, and paediatric and adult patients. The physicians were responsible for primary care in the ED and for critical care in the ICU. Both were staffed by board-certified attending physicians in emergency or intensive care medicine, or by anaesthesiologists, and by postgraduate residents (years 3-7) in emergency medicine, anaesthesiology and internal medicine. In addition, transitional postgraduate residents (years 1 and 2) rotated for several months in the EDs and ICUs. Most of the transitional year residents completed $\geq 1$ month of training in anaesthesiology in the operating room, during which they performed TI, using Macintosh in patients undergoing general anaesthesia, under the supervision of attending anaesthesiologists. When difficult airways or cervical instability were anticipated, the choice of VL was left to the discretion of the supervisors.

Three VLs, including the Pentax (Pentax-Airway Scope; AWS-S100, HOYA Corporation, Tokyo, Japan), King, (King Vision, King Systems, Noblesville, Indiana, USA) and McGrath (McGrath MAC; 300-000-000, Medtronic Inc, Minneapolis, Minnesota, USA) systems, as well as a Macintosh laryngoscope (Macintosh blade, KARL STORZ SE \& Co, Tuttingen, Germany) as a reference standard, were available in this study. These VLs had been commonly used prior to this study for several years in both institutions and there was no specific off-the-job training for these VLs. Channelled disposable blades were used with the King system. The laryngoscopes, drugs or operators for the TI procedures were chosen by the attending physician(s) without protocol. Using a handheld or fixed camera, the procedures were systematically video recorded for archival and quality control.

\section{Study participants}

We included consecutive video-recorded cases of emergency TI performed in the ED and ICU of both institutions between December 2013 and June 2015.

\section{Data collection and measurements}

We recorded the patient demographic and clinical characteristics; location of the TI (ED or ICU); indications for TI (cardiopulmonary arrest, airway obstruction, respiratory failure, haemodynamic instability or altered mental status); drugs used for TI (sedatives, analgesics and muscle relaxants); preprocedurally defined complicating airway characteristics including obesity (body mass index $\geq 28 \mathrm{~kg} / \mathrm{m}^{2}$ ), limited mouth opening (interincisor distance $<4 \mathrm{~cm}$ ), restricted neck mobilisation, short neck (thyromental distance $<6 \mathrm{~cm}$ ), facial trauma (diagnosed clinically and by imaging), oedema of the glottis visualised by the operator, and the presence of blood, secretions or vomitus in the airways requiring suction or interfering with the procedure. The laryngoscopes used, the length of clinical experience, and the specialty of the operators were recorded. The subjective difficulty, using a visual analogue scale between 0 (easy) and 100 (difficult) was scored by the operators. The first-pass intubation success rate, the number of attempts until successful TI, changes of laryngoscopes and operators, time between laryngoscope insertion into the mouth and the onset of ventilation after TI, complications (oedema or spasm of the glottis, dental injuries, regurgitation and airway haemorrhages), oesophageal intubations and the laryngoscope in use when the complication or the oesophageal intubation occurred, were recorded. The data were collected from the video recording for measurements of variables, in addition to medical records and a questionnaire. Data collection and analysis were performed by a single author (KS).

\section{Study endpoints}

The primary study endpoint was the first-pass intubation success rate, while the secondary endpoints were the time needed to perform the procedure, the subjective difficulty score, procedural complications and oesophageal intubation.

\section{Sample size and statistical analysis}

The estimated sample size was based on our own unpublished TI study performed by residents in patients undergoing elective surgery, in which the first-pass intubation success rates using the Macintosh and Pentax instruments were $64 \%$ and $90 \%$, respectively. Assuming a $20 \%$ difference in first-pass intubation success rates between the two 
Table 1 Baseline and difficult airway characteristics

\begin{tabular}{|c|c|c|c|c|c|c|}
\hline & $\begin{array}{l}\text { All } \\
(n=287)\end{array}$ & $\begin{array}{l}\text { Pentax-Airway } \\
\text { Scope }(n=82)\end{array}$ & $\begin{array}{l}\text { King VISION } \\
(n=59)\end{array}$ & $\begin{array}{l}\text { McGrath } \\
\text { Mac } \\
(n=82)\end{array}$ & $\begin{array}{l}\text { Macintosh } \\
(\mathrm{n}=64)\end{array}$ & $\mathbf{P}$ \\
\hline Men & $165(57.5)$ & $54(65.9)$ & $31(52.5)$ & $51(62.2)$ & $29(45.3)$ & 0.057 \\
\hline Age, years & $65.4 \pm 20.5$ & $60.7 \pm 24.8$ & $69.0 \pm 16.2$ & $67.4 \pm 17.1$ & $65.7 \pm 21.4$ & 0.457 \\
\hline Height, cm & $158.1 \pm 14.4$ & $156.9 \pm 19.3$ & $159.3 \pm 9.0$ & $160.9 \pm 10.2$ & $154.9 \pm 14.9$ & 0.044 \\
\hline Weight, kg & $55.9 \pm 13.9$ & $56.3 \pm 16.9$ & $56.2 \pm 10.2$ & $56.7 \pm 11.9$ & $54.0 \pm 15.2$ & 0.400 \\
\hline Body mass index & $22.0 \pm 3.7$ & $22.3 \pm 3.8$ & $22.1 \pm 3.6$ & $21.7 \pm 3.2$ & $22.1 \pm 4.2$ & 0.794 \\
\hline Expert operators & $131(45.6)$ & $36(43.9)$ & $27(45.8)$ & $45(54.9)$ & $23(35.9)$ & 0.149 \\
\hline $\begin{array}{l}\text { Location of tracheal intubation (ED/ } \\
\text { ICU) }\end{array}$ & $\begin{array}{l}162(56.4) / 125 \\
(43.6)\end{array}$ & $49(59.8) / 33(40.2)$ & $\begin{array}{l}37(62.7) / 22 \\
(37.3)\end{array}$ & $\begin{array}{l}37(45.1) / 45 \\
(54.9)\end{array}$ & $\begin{array}{l}39(60.9) / 25 \\
(39.1)\end{array}$ & 0.111 \\
\hline \multicolumn{7}{|l|}{ Indications for tracheal intubation } \\
\hline Cardiopulmonary arrest & $114(39.7)$ & 34 (41.5) & $26(44.1)$ & 25 (30.5) & $29(45.3)$ & 0.220 \\
\hline Airway obstruction & $14(4.9)$ & $4(4.9)$ & $1(1.7)$ & $7(8.5)$ & $2(3.1)$ & 0.305 \\
\hline Respiratory failure & $45(15.7)$ & $12(14.6)$ & $11(18.6)$ & $14(17.1)$ & $8(12.5)$ & 0.789 \\
\hline Haemodynamic instability & $32(11.1)$ & $6(7.3)$ & $2(3.4)$ & $20(24.4)$ & $4(6.3)$ & 0.000 \\
\hline Altered mental status & $82(28.6)$ & $26(31.7)$ & 19 (32.2) & $16(19.5)$ & $21(32.8)$ & 0.182 \\
\hline \multicolumn{7}{|l|}{ Drugs used for tracheal intubation } \\
\hline None & $148(51.6)$ & $44(53.7)$ & $32(54.2)$ & $35(42.7)$ & $37(57.8)$ & 0.274 \\
\hline Sedatives & $116(40.4)$ & $33(40.2)$ & $24(40.7)$ & $35(42.7)$ & $24(37.5)$ & 0.944 \\
\hline Analgesics & $91(31.7)$ & $22(26.8)$ & $15(25.4)$ & $36(43.9)$ & $18(28.1)$ & 0.053 \\
\hline Muscle relaxants & $59(20.6)$ & $15(18.3)$ & $10(16.9)$ & $22(26.8)$ & $12(18.8)$ & 0.450 \\
\hline $\begin{array}{l}\text { Drugs used for tracheal intubation in } \\
\text { non-CPA cases }\end{array}$ & $(n=173)$ & $(n=48)$ & $(n=33)$ & $(n=57)$ & $(n=35)$ & \\
\hline None & $34(19.7)$ & $10(20.8)$ & $6(18.2)$ & $10(17.5)$ & $8(22.9)$ & 0.925 \\
\hline Sedatives & $116(67.1)$ & $33(68.8)$ & $24(72.7)$ & $35(61.4)$ & $24(68.6)$ & 0.722 \\
\hline Analgesics & $91(52.6)$ & $22(45.8)$ & $15(45.5)$ & $36(63.2)$ & $18(51.4)$ & 0.250 \\
\hline Muscle relaxants & $59(34.1)$ & $15(31.3)$ & $10(30.3)$ & $22(38.6)$ & $12(34.3)$ & 0.842 \\
\hline \multicolumn{7}{|l|}{ Difficult airway characteristics } \\
\hline Obesity & $16(5.6)$ & $6(7.3)$ & $3(5.1)$ & $3(3.7)$ & $4(6.3)$ & 0.793 \\
\hline Limited mouth opening & $17(5.9)$ & $5(6.1)$ & $5(8.5)$ & $6(7.3)$ & $1(1.6)$ & 0.319 \\
\hline Restricted neck mobilisation & 39 (13.6) & 19 (23.2) & $6(10.2)$ & $7(8.5)$ & $7(10.9)$ & 0.040 \\
\hline Short neck & $9(3.1)$ & $3(3.7)$ & $1(1.7)$ & $3(3.7)$ & $2(3.1)$ & 0.937 \\
\hline Facial trauma & $13(4.5)$ & $7(8.5)$ & $1(1.7)$ & $4(4.9)$ & $1(1.6)$ & 0.171 \\
\hline Oedema of glottis & $7(2.4)$ & $2(2.4)$ & $0(0.0)$ & $4(4.9)$ & $1(1.6)$ & 0.390 \\
\hline $\begin{array}{l}\text { Bloods, secretion or vomitus in } \\
\text { airway }\end{array}$ & $123(42.9)$ & $36(43.9)$ & $23(39.0)$ & $38(46.3)$ & $26(40.6)$ & 0.821 \\
\hline $\begin{array}{l}\text { Cases with difficult airway } \\
\text { characteristics }\end{array}$ & $161(56.1)$ & $47(57.3)$ & $31(52.5)$ & $48(58.5)$ & $35(54.7)$ & 0.897 \\
\hline
\end{tabular}

Values are numbers (\%) of observations or means \pm SD.

CPA, cardiopulmonary arrest; ED, emergency department; ICU, intensive care unit.

laryngoscopes, we calculated a sample size of 62 procedures in each group at the $5 \% \alpha$ level and a power (1- $\beta$ ) of $80 \%$. Including missing data, we set the sample sizes of each group at 70 and a total of 280 procedures.

Categorical variables are expressed as counts and percentages and continuous variables as means \pm SD deviations. We compared the outcomes among the four laryngoscopes by Fisher's exact or Kruskal-Wallis tests. Procedures without an accurate measurement of the time needed to perform the TI from the video recording as well as those without subjective difficulty scores were excluded from the analysis. A post hoc analysis was performed by comparing all laryngoscopes pairwise to each other using Tukey-Kramer test. We also examined whether 
Table 2 First-pass intubation success rates of four laryngoscopes

\begin{tabular}{cllllll}
\hline & $\begin{array}{l}\text { All } \\
\text { laryngoscopes }\end{array}$ & $\begin{array}{l}\text { Pentax-Airway } \\
\text { Scope }\end{array}$ & King VISION & McGrath Mac & Macintosh & P value \\
\hline All operators, $n$ & 287 & 82 & 59 & 82 & 64 & \\
First-pass intubation success & $199(69)$ & $64(78)^{\star}$ & $34(58)$ & $64(78) \dagger$ & $37(58)$ & 0.004 \\
Non-expert operators & 156 & 46 & 32 & 37 & 41 & \\
First-pass intubation success & $104(67)$ & $40(87) \ddagger$ & $16(50)$ & $29(78) \S$ & $19(46)$ & 0.00004 \\
Expert operators & 131 & 36 & 27 & 45 & 23 & \\
\hline First-pass intubation success & $95(73)$ & $24(67)$ & $18(67)$ & $35(78)$ & $18(78)$ & 0.556 \\
\hline
\end{tabular}

Values are numbers (\%) of observations; post hoc analyses were performed using Tukey-Kramer test for paired comparisons of four laryngoscopes.

*vs King VISION $\mathrm{p}=0.043$; vs Macintosh $\mathrm{p}=0.039$.

tvs King VISION $\mathrm{p}=0.043$; vs Macintosh $\mathrm{p}=0.039$.

¥vs King VISION $p=0.002$; vs Macintosh $p<0.001$.

$\S v$ s King VISION $\mathrm{p}=0.043$; vs Macintosh $\mathrm{p}=0.009$.

the first-pass intubation success rates differed among the four laryngoscopes, in each prespecified subgroup, according to the duration of clinical experience (first and second postgraduate years as non-expert operators and $\geq$ third postgraduate year as experts). A logistic regression analysis was performed to identify factors influencing the first-pass intubation success rate. We included possible confounding factors that differed significantly among the four laryngoscopes (indication for TI and restricted neck mobility) and which were identified in previous studies (limited mouth aperture,${ }^{15}$ blood, secretion or vomitus in the airways, ${ }^{16}$ experts versus non-expert operator ${ }^{17}$ ). $P$ values $<0.05$ were considered statistically significant. The analyses were performed using IBM SPSS Statistics for Mac V.23.0 (IBM Corporation).

\section{Patient and public involvement statement}

Patients were not involved.

\section{RESULTS}

\section{Characteristics of the study population}

The patient characteristics are summarised in table 1. A total of 287 patients underwent video-recorded emergency TI. Among the indications for TI, haemodynamic instability differed significantly among the four laryngoscopes, with the McGrath most frequently used in the presence of haemodynamic instability. Complicating airway characteristics were present in $56 \%$ of cases, including blood, secretions or vomitus in the airways in 123 procedures (43\%). The Pentax was often used during procedures complicated by restricted neck mobility. Among the 67 non-experts, 57 operators $(89.1 \%)$ had received some anaesthesiology training in the operating room. They performed $33 \pm 14$ TIs, including $6 \pm 5$ procedures using Pentax or McGrath VLs. TI was interrupted in three cases $(1 \%)$, of which one was managed without TI; another underwent emergency cricothyroidotomy and a third suffered fatal cardiopulmonary arrest. In the remaining 284 procedures, TI was attempted once in 199 (69\%), twice in $49(17 \%)$ and
$>$ twice in 36 instances (13\%). The number of attempts until successful TI were $1.3 \pm 0.9$ with Pentax, $1.4 \pm 0.7$ with King, $1.3 \pm 0.6$ with McGrath and $1.5 \pm 0.7$ with Macintosh $(\mathrm{p}=0.007)$. The laryngoscope was replaced in 22 cases $(8 \%)$. Out of 59 procedures, the King was replaced by another laryngoscope in nine instances $(15 \% ; \mathrm{p}=0.043 \mathrm{vs}$ other groups). The King was replaced by another device in seven procedures because of separation of the laryngoscope from its disposable blade. The operator was replaced in 21 attempts at TI (7\%), of which 19 were initially made by a non-expert operator. The number of operators was similarly replaced in the four study groups.

\section{Main results}

The overall first-pass intubation success rate was $69 \%$ and differed significantly $(\mathrm{p}=0.004)$ among the four laryngoscopes (table 2). In post hoc analysis, the first-pass intubation success rates were higher for the Pentax and McGrath than those with the King or Macintosh laryngoscopes, respectively, although there were no significant differences in the expert operators' subgroup (table 2). Overall, non-experts and experts showed similar first-pass intubation success rates of $67 \%$ and $73 \%$, respectively. Logistic regression analysis with adjustments for the indication for TI, restricted neck mobilisation, limited mouth opening, blood/secretion/vomitus in the airway, and experts/non-expert revealed that the ORs for firstpass intubation success were significantly higher for the Pentax and McGrath laryngoscopes than that for the King laryngoscope when compared with the Macintosh laryngoscope (table 3 ).

There were significant differences in the times needed to perform TI among the four laryngoscopes, although no differences were observed in pairwise comparisons of the laryngoscopes in the post hoc analysis (table 4). There was a significant difference in the difficulty scores among the four laryngoscopes, with the McGrath significantly easier to use than the Macintosh in post hoc analysis (table 4). 
Table 3 Multiple variable analysis of factors influencing the first-pass intubation success rates

\begin{tabular}{|c|c|c|c|}
\hline Factors & ORs & $95 \% \mathrm{Cls}$ & $P$ value \\
\hline \multicolumn{4}{|l|}{ Laryngoscopes } \\
\hline $\begin{array}{l}\text { Macintosh } \\
\text { (reference) }\end{array}$ & 1 & - & - \\
\hline $\begin{array}{l}\text { Pentax-Airway } \\
\text { Scope }\end{array}$ & 3.422 & 1.551 to 7.550 & 0.002 \\
\hline King VISION & 1.056 & 0.487 to 2.289 & 0.889 \\
\hline McGrath Mac & 3.758 & 1.640 to 8.612 & 0.002 \\
\hline \multicolumn{4}{|c|}{ Indications for tracheal intubation } \\
\hline $\begin{array}{l}\text { Cardiopulmonary } \\
\text { arrest }\end{array}$ & 1 (reference) & & \\
\hline $\begin{array}{l}\text { Airway } \\
\text { obstruction }\end{array}$ & 0.226 & 0.063 to 0.812 & 0.023 \\
\hline Respiratory failure & 0.720 & 0.284 to 1.822 & 0.488 \\
\hline $\begin{array}{l}\text { Haemodynamic } \\
\text { instability }\end{array}$ & 0.380 & 0.137 to 1.054 & 0.063 \\
\hline $\begin{array}{l}\text { Altered mental } \\
\text { status }\end{array}$ & 0.361 & 0.180 to 0.723 & 0.004 \\
\hline \multicolumn{4}{|c|}{ Difficult airway characteristics } \\
\hline \multicolumn{4}{|l|}{ Mouth opening } \\
\hline Unlimited & 1 (reference) & - & - \\
\hline Limited & 0.092 & 0.026 to 0.323 & 0.000 \\
\hline \multicolumn{4}{|l|}{ Neck mobility } \\
\hline Unrestricted & 1 (reference) & - & - \\
\hline Restricted & 0.951 & 0.414 to 2.182 & 0.905 \\
\hline \multicolumn{4}{|c|}{ Blood, secretions, vomitus in the airways } \\
\hline Absent & 1 (reference) & - & - \\
\hline Present & 0.455 & 0.257 to 0.804 & 0.007 \\
\hline \multicolumn{4}{|l|}{ Operators } \\
\hline Non-expert & 1 (reference) & - & - \\
\hline Expert & 1.688 & 0.916 to 3.108 & 0.093 \\
\hline
\end{tabular}

TI complications occurred in 21 procedures (7\%), consisting of one dental trauma, seven spasms or oedemas of the glottis, five instances of regurgitation and 10 haemorrhages, although there were no significant differences among the four laryngoscopes. The oesophagus was intubated in three instances $(1.2 \%)$ by non-experts using the Macintosh.

\section{DISCUSSION}

In this retrospective, observational, two-centre study, the first-pass intubation success rates for emergency TI were significantly higher for Pentax or McGrath laryngoscopes than for King or Macintosh laryngoscopes when performed by non-expert operators. After adjusting for confounding factors, the ORs for first-pass intubation success were significantly higher for the Pentax and McGrath laryngoscopes than that for the King laryngoscope, when compared with the Macintosh laryngoscope. The use of the McGrath was associated with a lower subjective difficulty of performing TI than that for the use of the Macintosh.

A previous study of VLs for TI by experienced anaesthetists in the operating room revealed a better visualisation of the glottis with the Pentax than that with the Macintosh, while the success rates and TI procedure times were similar. ${ }^{8}$ Moreover, studies with inexperienced residents reported a $96 \%$ first-pass intubation success rate with the Pentax versus $70 \%$ with the Macintosh and 44 and 71 s, respectively, to secure the airways. ${ }^{9}$ Our results are concordant with these success rates, suggesting the advantageous characteristics of the Pentax, particularly for novice operators. The suitable shape of the PBLADE, which indirectly visualises the glottis regardless of the head and neck position, the existence of a blade channel to set the tracheal tube, and the guiding function of the target mark on the screen support the preferential use of the Pentax among the VLs. ${ }^{18}$

The McGrath is a relatively compact device without a tracheal tube guide channel. ${ }^{19}$ Like the Macintosh, it offers an indirect view of the glottis by flexible manipulations of the laryngoscope and tracheal tube. Several factors, therefore, such as a restricted neck mobility or the operator's experience with TI, might influence the success rate of the Pentax versus the McGrath. However, the first-pass intubation success rates were nearly the same between these VLs in this study population. A randomised study comparing the performance of Pentax versus McGrath in emergency TI is, therefore, warranted.

The use of a stylet facilitates the manipulation of the tracheal tube adjacent to the glottis. However, a randomised clinical trial in the ICU population, which showed no improvement in a McGrath-used first-pass intubation, did not use a stylet, which was used in all

Table 4 Comparisons of times needed to perform tracheal intubations and of difficulty scores for four different laryngoscopes

\begin{tabular}{lllllll}
\hline & & Pentax-Airway & & & & \\
& Overall & Scope & King VISION & McGrath Mac & Macintosh & P \\
\hline Time to perform intubations, s & $60 \pm 31(n=269)$ & $63 \pm 34(n=78)$ & $63 \pm 31(n=45)$ & $62 \pm 31(n=79)$ & $52 \pm 27(n=67)$ & 0.043 \\
Difficulty score + & $39 \pm 27(n=258)$ & $39 \pm 26(n=72)$ & $43 \pm 26(n=45)$ & $32 \pm 27^{*}(n=78)$ & $45 \pm 26(n=63)$ & 0.009 \\
\hline
\end{tabular}

Values are means \pm SD deviations.

post hoc analyses were performed using Tukey-Kramer test for paired comparisons of four laryngoscopes.

${ }^{*} \mathrm{p}=0.027$ vs Macintosh.

†Difficulty was scored by visual analogue scale, from very easy (0) to very difficult (100). 
McGrath cases here. ${ }^{20}$ This may be the reason for the nonconformance between the studies' results.

To our knowledge, the present study was the first to compare the Pentax and King in clinical settings. Although they have similar shapes and tracheal tube guiding characteristics, the first-pass intubation success rate was significantly lower for the King than that for the Pentax. The orientation of the King tracheal tube is relatively downward compared with that of the Pentax, which may interfere with its advancement. In addition, the King has no marking to help in the placement of the tube. System malfunction, which occurred in seven patients in this study, may also have lowered the success rate of the King.

Several factors, which varied among the four laryngoscopes, had repercussions on the success rate of TI. Blood or vomitus in the airways, an important complication when performing emergency TI, may lower the image quality. Blood, secretions or vomitus were present in the airways in $43 \%$ of procedures, significantly lowering the first-pass intubation success rate. ${ }^{16}$ However, after adjusting for this factor, multiple variable analysis confirmed the advantage of the Pentax and McGrath. A limited mouth aperture was also correlated with the difficulty of TI. ${ }^{15}$ This, however, was problematic in only $6 \%$ of cases and did not represent a major obstacle to the insertion of the devices.

The results of the present study suggest the usefulness of the Pentax or McGrath VLs for emergency TI performed by novice physicians. However, the generalisability of the results for intubation in other settings (in the operating theatre or prehospital settings, or by non-physicians) remains uncertain.

Systematic review and meta-analysis of randomised controlled trials revealed that video laryngoscopy does not improve first-attempt intubation success rates compared with that of direct laryngoscopy in emergency, critical and surgical patients. ${ }^{21}{ }^{22}$ However, multiple models of VLs with various characteristics were combined as a ' $\mathrm{VL}$ group' in the analysis. Here, we intended to compare the individual performances of VLs.

\section{Study limitations}

This was an observational study, in which confounding factors may have influenced the success rate of TI and biased the results. However, after adjusting for possible confounding factors based on those reported in previous studies, we observed a significant relationship between VLs and first-pass intubation success rates. We included video-recorded cases of TI during the study period. Unfortunately, only $22 \%$ of cases were recorded due to the limited availability of physicians who were able to operate the video cameras. Thus, there might be a selection bias. The data collection and analysis were performed by a single author (KS), leaving the potential for observer bias. Furthermore, we classified the 'non-experts' based on their clinical experience. A precise index to grade the level of intubation skill might have been preferable, although it does not currently exist. Finally, bias based on operator familiarity with each laryngoscope cannot be excluded. However, given the scarce overall experience of TI itself prior to this study (4.6 times/person), the results of the non-expert group are likely to be less biased.

\section{CONCLUSION}

When performing emergency TI in the ED or the ICU, the use of the Pentax and McGrath laryngoscopes were associated with significantly higher first-pass intubation success rates than that of the King laryngoscope when compared with the Macintosh laryngoscope, especially when operated by non-experts.

Acknowledgements We thank the attending physicians and residents of the Department of Emergency and Critical Care Medicine of Hiroshima University and the Critical Care Medical Center of Hiroshima Prefectural Hospital who contributed to the data collection.

Contributors KS conceived the study, designed the trial and collected and managed the data. SK, KT and NS supervised the conduct of the trial and data collection. KS drafted the manuscript and all authors contributed substantially to its revision. KS takes responsibility for the paper as a whole.

Funding This work was supported by KAKENHI Grants from the Japan Society for the Promotion of Science (JSPS) (Numbers JP 17K11573).

Competing interests None declared.

Patient consent for publication Not required.

Ethics approval This study was reviewed and approved by the research ethics committees of Hiroshima University (No 1069) and Hiroshima Prefectural Hospital (No 2013-76).

Provenance and peer review Not commissioned; externally peer reviewed.

Data sharing statement The data included deidentified participant data. The data are available from author (KS, e-mail: suzukik@hiroshima-u.ac.jp).

Open access This is an open access article distributed in accordance with the Creative Commons Attribution Non Commercial (CC BY-NC 4.0) license, which permits others to distribute, remix, adapt, build upon this work non-commercially, and license their derivative works on different terms, provided the original work is properly cited, appropriate credit is given, any changes made indicated, and the use is non-commercial. See: http://creativecommons.org/licenses/by-nc/4.0/.

\section{REFERENCES}

1. Martin LD, Mhyre JM, Shanks AM, et al. 3,423 emergency tracheal intubations at a university hospital: airway outcomes and complications. Anesthesiology 2011;114:42-8.

2. Schmidt UH, Kumwilaisak K, Bittner E, et al. Effects of supervision by attending anesthesiologists on complications of emergency tracheal intubation. Anesthesiology 2008;109:973-7.

3. Benedetto WJ, Hess DR, Gettings E, et al. Urgent tracheal intubation in general hospital units: an observational study. J Clin Anesth 2007;19:20-4.

4. Schwartz DE, Matthay MA, Cohen NH. Death and other complications of emergency airway management in critically ill adults. A prospective investigation of 297 tracheal intubations. Anesthesiology 1995;82:367-76.

5. Simpson GD, Ross MJ, McKeown DW, et al. Tracheal intubation in the critically ill: a multi-centre national study of practice and complications. Br J Anaesth 2012;108:792-9.

6. Liu L, Tanigawa K, Kusunoki S, et al. Tracheal intubation of a difficult airway using Airway Scope, Airtraq, and Macintosh laryngoscope: a comparative manikin study of inexperienced personnel. Anesth Analg 2010;110:1049-55.

7. Carlson JN, Brown CA. Does the use of video laryngoscopy improve intubation outcomes? Ann Emerg Med 2014;64:165-6.

8. Teoh WH, Saxena S, Shah MK, et al. Comparison of three videolaryngoscopes: Pentax Airway Scope, C-MAC, Glidescope vs the Macintosh laryngoscope for tracheal intubation. Anaesthesia 2010;65:1126-32. 
9. Hirabayashi $\mathrm{Y}$, Seo N. Tracheal intubation by non-anaesthetist physicians using the Airway Scope. Emerg Med J 2007;24:572-3.

10. Taylor AM, Peck M, Launcelott S, et al. The McGrath ${ }^{\circledR}$ Series 5 videolaryngoscope vs the Macintosh laryngoscope: a randomised, controlled trial in patients with a simulated difficult airway. Anaesthesia 2013;68:142-7.

11. Janz DR, Semler MW, Lentz RJ, et al. Randomized Trial of Video Laryngoscopy for Endotracheal Intubation of Critically III Adults. Crit Care Med 2016;44:1980-7.

12. Rombey T, Schieren M, Pieper D. Video versus direct laryngoscopy for inpatient emergency intubation in adults: a systematic review and meta-analysis of randomized controlled trials. Dtsch Arztebl Int 2018;115:437-44.

13. Hasegawa K, Shigemitsu K, Hagiwara Y, et al. Association between repeated intubation attempts and adverse events in emergency departments: an analysis of a multicenter prospective observational study. Ann Emerg Med 2012;60:749-54.

14. Sakles JC, Chiu S, Mosier J, et al. The importance of first pass success when performing orotracheal intubation in the emergency department. Acad Emerg Med 2013;20:71-8.

15. Breckwoldt J, Klemstein S, Brunne B, et al. Difficult prehospital endotracheal intubation - predisposing factors in a physician based EMS. Resuscitation 2011;82:1519-24.
16. Gaither JB, Spaite DW, Stolz U, et al. Prevalence of difficult airway predictors in cases of failed prehospital endotracheal intubation. $J$ Emerg Med 2014;47:294-300.

17. Crewdson K, Lockey DJ, Røislien J, et al. The success of prehospital tracheal intubation by different pre-hospital providers: a systematic literature review and meta-analysis. Crit Care 2017;21:31.

18. Koyama J, Aoyama T, Kusano Y, et al. Description and first clinical application of AirWay Scope for tracheal intubation. $J$ Neurosurg Anesthesiol 2006;18:247-50.

19. Kotera A, Irie H, Iwashita S, et al. Comparison of the McGrath MAC video laryngoscope and the Pentax Airwayscope during chest compression: a manikin study. J Intensive Care 2014;2:18

20. Lascarrou JB, Boisrame-Helms J, Bailly A, et al. Video Laryngoscopy vs Direct Laryngoscopy on Successful First-Pass Orotracheal Intubation Among ICU Patients: A Randomized Clinical Trial. JAMA 2017;317:483-93.

21. Jiang J, Ma D, Li B, et al. Video laryngoscopy does not improve the intubation outcomes in emergency and critical patients - a systematic review and meta-analysis of randomized controlled trials. Crit Care 2017;21:288

22. Lewis SR, Butler AR, Parker J, et al. Videolaryngoscopy versus direct laryngoscopy for adult patients requiring tracheal intubation. Cochrane Database Syst Rev 2016;11:CD011136. 